El-Raouf Taha trên 96 bệnh nhân tại trường đại học Zagazig có tiên sử mắc bệnh dị ứng, kết quả nghiên cứu cũng cho thấy đa số bệnh nhân dị ứng với mạt bụi nhà Dp (81,2\%), mạt bụi nhà Df $(79,2 \%)$ và mạt bụi nhà là dị nguyên gây dị ứng phổ biến nhất cho con người nói chung một cách có ý nghĩa thống kê với $p<0,001[6]$.

Kết quả nghiên cứu ghi nhận 49 trường hợp (79\%) bi khô cả hai mắt (tỷ lệ khô mắt phải $80,6 \%$ và mắt trái là $85,5 \%$ ). Kết quả này cao hơn rất nhiều so với nghiên cứu của Handan Akil và cộng sự trên 25 trẻ tuổi từ 6 đến 18 được chẩn đoán viêm kết mạc dị ứng thì khô mắt có tỷ lệ 40\%. Có sự khác biệt này có thể do có sự khác biệt về đối tượng nghiên cứu, mức độ bệnh và địa dư [7].

\section{KẾT LUẬN}

Số bệnh nhân viêm kết mạc dị ứng theo mùa là $49(79 \%), 13(21 \%)$ bệnh nhân viêm kết mạc dị ứng quanh năm. Trong đó $35(56,5 \%)$ là nam giới, $27(43,5 \%)$ là nữ giới với độ tuổi trung bình là 22,02 tuổi.Bệnh nhân tập trung nhiều ở nhóm tuổi $\geq 19$ (50\%), tiếp theo ở nhóm tuổi 6-11 tuổi (33,9\%). -

Triệu chứng lâm sàng $100 \%$ bệnh nhân có ngứa, tiếp theo là các triệu chứng chảy nước mắt, kết mạc cương tụ ở các mức độ. Triệu chứng sợ ánh sáng và viêm chấm nông biểu mô ít gặp, chỉ mức độ nhẹ hoặc không có.

Có 58 bệnh nhân $(93,5 \%)$ dị ứng với từ 2 loại dị nguyên trở lên, mạt bụi nhà Df, Dp, Bt và Gián Mỹ là các loại dị nguyên gây dị ứng hay gặp.

Có $79 \%$ bệnh nhân bị khô cả hai mắt có thời gian BUT ngắn.

\section{TÀI LIÊU THAM KHẢO}

1. Kubaisi, B., K. Samra, and S. Syeda, Ocular Allergy: an Updated Review. J Allergy Immunol, 2017. 1: p. 002.

2. Kamis, U., et al., Comparison of the efficacy of olopatadine hydrochloride $0.1 \%$ ophthalmic solution and artificial tears in seasonal allergic conjunctivitis. Acta Ophthalmol Scand, 2006. 84(1): p. 148-9.

3. Bilkhu, P.S., et al., Effectiveness of nonpharmacologic treatments for acute seasonal allergic conjunctivitis. Ophthalmology, 2014. 121(1): p. 72-78.

4. Dupuis, P., et al., A contemporary look at allergic conjunctivitis. Allergy, Asthma \& Clinical Immunology, 2020. 16(1): p. 5.

5. Abo-Ali, F.H., et al., Skin Prick Test Reactivity to Aeroallergens among Egyptian Patients with Isolated Allergic Conjunctival. EGYPTIAN JOURNAL OF IMMUNOLOGY, 2015. 22(2): p. 41-47.

6. Taha, A.A.E., et al., House dust mites among allergic patients at the Allergy and Immunology Unit, Zagazig University: an immunologic and serologic study. J Parasit Dis, 2018. 42(3): p. 405-415.

7. Akil, H., et al., Dry eye syndrome and allergic conjunctivitis in the pediatric population. Middle East African journal of ophthalmology, 2015. 22(4): p. 467.

\title{
ĐÁNH GIÁ KẾT QUẢ BƯớC ĐẦU PHỐI HỢP TRA AZARGA VÀ TIÊM BEVACIZUMAB NộI NHÃN TRONG ĐIỀU TRI PHÙ HOÀNG ĐIỂM DO ĐÁI THÁO ĐƯờNG
}

\section{TÓM TẮT.}

Mục tiêu: Đánh giá kết quả bước đầu phối hợp tra Azarga và tiêm Bevacizumab nội nhãn trong điểu trị phù hoàng điểm do đái tháo đường về mặt giải phẩu và chức năng. Đối tượng và phương pháp: Nghiên cứu thử nghiệm lâm sàng có đối chứng trên cưng bệnh nhân, 30 mắt được tra Azarga 2 lần/ngày và tiêm Bevacizumab nội nhã̃n $(1,25 \mathrm{mg} / 0,05 \mathrm{ml} / \mathrm{mũi})$ hàng tháng với 30 mắt tiêm Bevacizumab đơn thuân liều tương tự trong 3 tháng điều trị phù hoàng điểm do đái tháo đường tại khoa Dịch kính - Võng mạc

\footnotetext{
${ }^{1}$ Trường Đại hơ Y Hà Nôi

${ }^{2}$ Bênh viên Mắt Trung Ương

Chịu trách nhiệm chính: Nguyễn Diệu Thu

Email: dieuthunguyen161192@gmail.com

Ngày nhận bài: 9.8.2021

Ngày phản biên khoa hoc: 4.10 .2021

Ngày duyệt bài: 14.10 .2021
}

\section{Nguyễn Diệu Thu ${ }^{1}$, Đặng Trần Đạt ${ }^{2}$, Mai Quốc Tùng ${ }^{1}$}

Bênh viện Mắt Trung ương từ tháng 8/2020 đến tháng 5/2021. Kết quả: 30 bênh nhân (16 nữ) được chẩn đoán là $2 \mathrm{M}$ phù hoàng điểm do đái tháo đường. Chiêu dày, thể tích vùng vông mạc trung tâm và thị lực đều cải thiện ở cả 2 nhóm mắt, nhãn áp ở 2 nhóm mắt không có sự thay đổi đáng kể. Trong đó nhóm mắt phối hợp tra Azarga và tiêm Bevacizumab nội nhãn kết quả điêu trị tốt hơn so với nhóm mắt tiêm Bevacizumab nội nhãn đơn thuân về mức độ cải thiện chiều dày vùng võng mạc trung tâm (CMT) là có ý nghĩa thống kề. Sự khác nhau về $\mathrm{CMT}$ trung bình và thể tích vùng võng mạc trung tâm hay thi lực giữa 2 nhóm mắt chưa có ý nghĩa thống kê. Kết İuận:Việc phối hợp tra Azarga và tiêm Bevacizumab nội nhã̉n bước đầu có xu hướng hiệu quả hơn so với tiêm Bevacizumab đơn thuần trong điêuu trị phù hoàng điểm do đái tháo đường về giải phẫu và chức năng, nhưng bước đâuu mới thể hiện rõ ở mức độ cải thiện về giải phẫu (chiều dày vùng võng mạc trung tâm).

Tư khóa: Azarga, Tiêm Bevacizumab nội nhãn; 
Phù hoàng điểm do đái tháo đường, Chiêuu dày võng mạc trung tâm, Thể tích vùng võng mạc trung tâm, Thị lực.

\section{SUMMARY \\ THE FIRST RESULT OF ADJUVANT TOPICAL AZARGA WITH INTRAVITREAL BEVACIZUMAB INJECTION IN DIABETIC MACULAR EDEMA \\ Purpose: To assess the first result of adjuvant} topical azarga with intravitreal bevacizumab (IVB) injection on anatomy and function in eyes affected with diabetic macular edema (DME). Methods: Thirty patients with bilateral DME who were treatment-naive were enrolled. Enrolled patients received a treatment plan of topical azarga twice daily in the interventional eye. Three monthly bilateral IVB injections $1.25 \mathrm{mg} / 0.05 \mathrm{~mL}$ were also planned. Baseline central macular thickness (CMT) and central macula volume (CMV) were measured by spectral-domain optical coherence tomography (SD-OCT), clinical information such as best corrected visual acuity (BCVA) and intraocular pressure (IOP) were collected at enrollment and one month after the third injection. Results: Thirty patients with DME were included. BCVA, CMT and CMV improved and normal IOP in both eyes. In repeated measures ANOVA analysis, There are many differences of improvement in anatomic and functional results between two groups, but the difference of improvement the CMT were significant in the interventional eye. Conclusion: Our study proved that first result of adjuvant topical azarga in combination with IVB is more effective than IVB alone with improvement in anatomy (central macular thickness) in eyes with DME. This study also suggested that improvement in central macular volume and in function (visual acuity, intraocular pressure) of adjuvant topical azarga in combination with IVB will be obvious the following treatment months.

Keywords: Azarga, Intravitreal bevacizumab, Diabetic macular edema, Macular thickness, Macular volume, Visual acuity.

\section{I. ĐĂT VẤN ĐỀ}

Phù hoàng điểm do đái tháo đường là nguyên nhân gây giảm thị lực chủ yếu ở bệnh nhân võng mạc đái tháo đường. ${ }^{1}$ Việc sử dụng các thuốc chống tăng sinh tân mạch như: Bevacizumab (Avastin), Ranibizumab (Lucentis), Aflibercept (Eylea) được coi là điều trị tiêu chuẩn trong phù hoàng điểm do đái tháo đường. 2,3 Tuy nhiên, khoảng $20-30 \%$ bệnh nhân có đáp ứng kém hoăc rất chậm với thuốc anti-VEGF đơn thuần, trở thành rào cản trong điều trị bệnh lý này. ${ }^{4-6}$ Để tăng tỷ lệ thành công trong điều trị, đã có nhiều phương pháp điều trị phối hợp giữa tiêm nội nhãn anti-VEGF (Bevacizumab) với các thuốc hạ nhãn áp chẹn kênh Calci tra tại chố như Timolol-dorzolamid bước đầu thấy hiệu quả tốt hơn so với tiêm nội nhãn anti-VEGF đơn thuần. 5,7,8 Tại Việt Nam, đại diện nhóm thuốc phối hợp Timolol-dorzolamid đang được sử dụng phổ biến là Azarga nhưng mới chỉ điều trị bệnh lý glôcôm đơn thuần. Với mong muốn cải thiện hiệu quả điều trị tối ưu cho thuốc anti-VEGF mà lại tiết kiêm kinh phí cho những bênh nhân phù hoàng điểm do đái tháo đường trong điều kiện tại Việt Nam, việc phối hợp giữa thuốc anti-VEGF là Bevacizumab với Azarga mang nhiều hứa hẹn khả quan.

\section{II. ĐỐI TƯợNG VÀ PHƯƠNG PHÁP NGHIÊN CứU}

2.1. Đối tượng nghiên cứu. Nghiên cứu được tiến hành trên nhóm bệnh nhân bị phù hoàng điểm do bênh võng mạc đái tháo đường cả hai mắt tại khoa Dịch kính - Võng mạc, Bệnh viện Mắt Trung ương từ tháng 8/2020 đến tháng $5 / 2021$.

Nghiên cứu loai trừ những trường hợp bê̂nh nhân đã sử dụng bất kì phương pháp điều trị bệnh trong 3 tháng gần đây, có màng trước võ̃ng mạc, hoặc đang mắc kèm bệnh lý tại mắt và toàn thân đang tiến triển nặng, tiền sử phẫu thuật dịch kính võng mạc, bệnh glôcôm có dùng thuốc chẹn $\beta$ giao cảm hay ức chế men chuyển carbonic anhydrase kéo dài.

\subsection{Phương pháp nghiên cứu}

2.2.1. Thiết kế nghiên cứu. Thử nghiệm lâm sàng ngẫu nhiên có nhóm chứng.

Cõ mẫu: 30 mắt/ nhóm

Cách chọn mẫu: chọn các bệnh nhân có phù hoàng điểm do đái tháo đường cả 2 mắt, mứ̛́c độ phù tương đương nhau, sau đó phân ngẫu nhiên 1 mắt vào nhóm nghiên cứu (can thiệp), mắt còn lại vào nhóm chứng.

\subsubsection{Các bước nghiên cứu}

- Khám trước điều trị: Hỏi bệnh, khám lâm sàng, khám cận lâm sàng.

- Điều trị: Nhóm mắt nghiên cứu (NC): tiến hành tiêm 3 nội nhãn Bevacizumab (Avastin, Genentech) 1,25mg/0,05ml (1 mũi/tháng) phối hợp tra tại chỗ dung dịch Azarga (Alcon) 2 lần/24h trong 3 tháng liên tục. Nhóm mắt chứng: tiến hành tiêm nội nhãn 3 mũi Bevacizumab (liều tương tự) đợn thuần.

- Theo dõi bệnh nhân: Ngay sau tiêm (đo nhãn áp, khám sinh hiển vi); khám lại, theo dõi, đánh giá sau điều trị.

\section{3. Đánh giá kết quả (trước- trong-sau} điêu trị)

*Giải phẫu:

- Chiều dày võng mạc trung tâm (CMT) trung bình; mức độ cải thiện chiều dày võng mạc trung

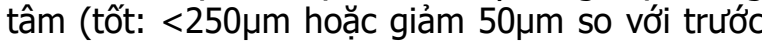
điều trị, trung bình: $250-400 \mu \mathrm{m}$, xấu: $>400 \mu \mathrm{m})$.

- Thể tích vùng võng mạc trung tâm (CMV) trung bình. 
*Chức năng:

- Thị lực: Thị lực trung bình; mức độ cải thiện thị lực (tốt: logMAR giảm > 0,3 hay thị lực tăng trên 3 hàng; ổn định: logMAR giảm $0-0,3$ hay thị lực tăng từ 1 chữ đến 3 hàng; giảm: logMAR tăng hay thị lực giảm từ 1 chữ trở lên).

- Nhãn áp: nhãn áp thấp $(<15 \mathrm{mmHg})$, bình thường $(15-24 \mathrm{mmHg})$, cao $(>24 \mathrm{mmHg})$.

Biến chứng: các tai biến trong tiêm và biến chứng sau tiêm.

\section{Đăc điểm phù hoàng điểm trước điều tri:}

\section{Bảng 1. Đặc điểm phù hoàng điểm trước điều trị của 2 nhóm mắt}

\begin{tabular}{|c|c|c|c|}
\hline Nhóm & Nhóm mắt nghiên cứu & Nhóm mắt chứng & $\mathbf{P}$ \\
\hline Tiêu chí & $408,2 \pm 126,1$ & $379,5 \pm 102,3$ & 0,104 \\
\hline Chiếu dày võng mạc trung tâm $(\mu \mathrm{m})$ & $13,24 \pm 2,64$ & $12,58 \pm 1,99$ & 0,091 \\
\hline Thể tích võng mạc trung tâm $\left(\mathrm{cm}^{3}\right)$ & $0,79 \pm 0,35$ & $0,87 \pm 0,39$ & 0,337 \\
\hline Thị lực (logMAR) & $17,53 \pm 1,14$ & $17,70 \pm 1,02$ & 0,407 \\
\hline Nhãn áp $(\mathrm{mmHg})$ & 3014
\end{tabular}

Trước điều trị, đặc điểm về phù hoàng điểm của 2 nhóm khá tưởng đồng, không có sự khác nhau có ý nghĩa thống kê, với p>0,05.

Cụ thể, về mặt giải phẫu, chiều dày và thể tích vùng võng mạc trung tâm trung bình của nhóm mắt nghiên cứu (NC) cao hơn nhóm mắt chứng nhưng không có ý nghĩa thống kê,với $p>0,05$.

Về mặt chức năng, thị lực trung bình nhóm mắt nghiên cứu cao hơn thị lực nhóm mắt chứng, cũng không có ý nghĩa thống kê với $p>0,05$. Nhãn áp của tất cả các mắt của 2 nhóm đều trong giới hạn bình thường, trong đó nhãn áp của 2 nhóm có sự tương đồng, với p>0,05.

\subsection{Kết quả nghiên cứu}

*Chiều dày vùng vông mạc trung tâm

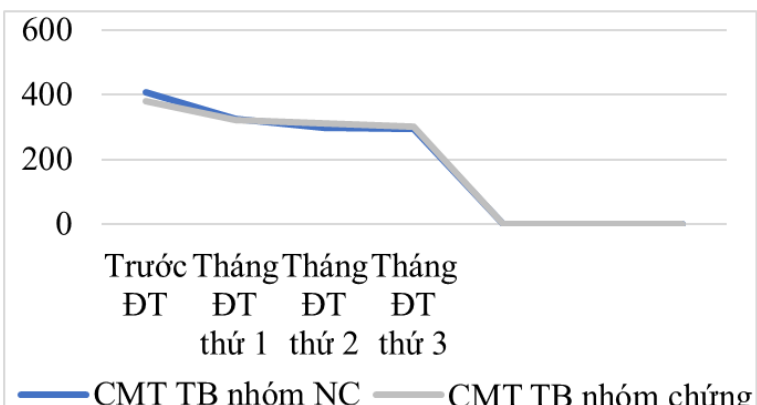

Biểu đồ 2. Sự thay đổi chiều dày vùng VMTT (CMT) trung binh của 2 nhóm mắt.

Sự thay đổi về chiều dày VMTT trung bình qua các giai đoạn điêu trị của nhóm mắt nghiên cứu khác với nhóm mắt chứng.

- Chiều dày vùng võng mạc trung tâm (VMTT) trung bình của 2 nhóm mắt: nhóm nghiên cứu là $295,5 \pm 10,8 \mu \mathrm{m}$ với $\mathrm{p}=0,000$; nhóm chứng là

\section{KẾT QUẢ NGHIÊN CỨU}

3.1. Đặc điểm bệnh nhân. Nghiên cứu trên 30 bệnh nhân ( 30 mắt/ nhóm) phù hoàng điểm do đái tháo đường với những đặc điểm sau:

Đặc điểm chung: Nhóm bểnh nhân có tuổi trung bình là $59,7 \pm 9,8$ (thấp nhất là 31 , cao nhất là 77 ), với tỉ lệ về giới nữ $53 \%$, nam $47 \%$; chủ yếu mắc đái tháo đường type $2(90 \%)$, giai đoạn tổn thương chủ yếu là chưa tăng sinh $(80 \%)$, chưa tăng sinh $(20 \%)$.

$301,3 \pm 14,5 \mu \mathrm{m}$ với $\mathrm{p}=0,002$. Trong đó, chiều dày VMTT trung bình nhóm nghiên cứu khác biệt với nhóm chứng,với $p=0,692$.

- Mức độ cải thiện chiều dày vùng VMTT của 2 nhóm mắt có sự khác nhau: nhóm mắt nghiên cứu là: tốt $63,3 \%$, trung bình $26,7 \%$, xấu 10,0\%; nhóm chứng: tốt 30,0\%, trung bình $56,7 \%$, xấu $13,3 \%$; trong đó mức độ cải thiện chiều dày võng mạc trung tâm của nhóm mắt nghiên cứu khác với nhóm mắt chứng, $\mathrm{p}=0,02$.

*Thể tích vùng vông mac trung tâm (CMV). Thể tích vùng VMTT trung bình của 2 nhóm mắt sau tháng điều trị thứ 3 là: nhóm nghiên cứu: $11,20 \pm 0,29 \mathrm{~cm}^{3}$, với $\mathrm{p}=0,000$; nhóm chứng: $11,24 \pm 0,27 \mathrm{~cm}^{3}$, với $p=0,000$. Trong đó, thể tích vùng VMTT trung bình nhóm nghiên cứu có khác biệt với nhóm chứng, với $p=0,101$.

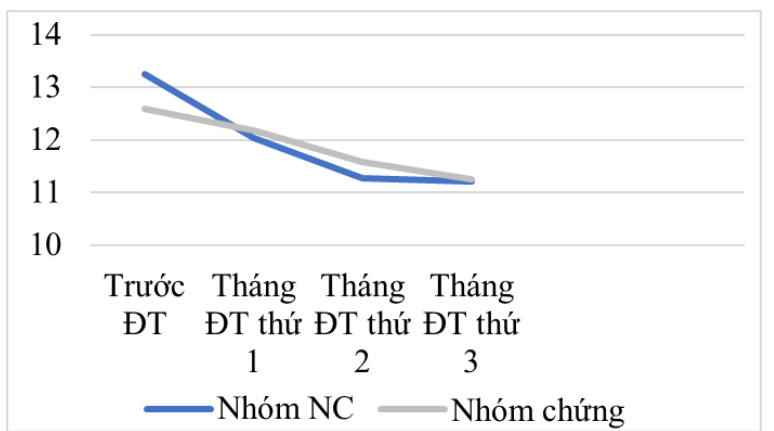

\section{Biểu đồ 3. Sư thay đổi thể tích vùng VMTT của 2 nhóm qua các giai đoạn điều trị}

Có sự thay đổi khác nhau về thể tích vùng VMTT của 2 nhóm qua các giai đoạn điều trị.

Sự thay đổi thể tích vùng VMTT của 2 nhóm mắt sau tháng ĐT thứ 3 so với trước điều trị: 
nhóm NC giảm $1,70 \pm 1,90 \mathrm{~cm}^{3}$, nhóm chứng giảm $1,34 \pm 1,64 \mathrm{~cm}^{3}$; sự thay đổi khác nhau giữa 2 nhóm, với $\mathrm{p}=0,256$.

*Về thi lức

- Thị lực trung bình của 2 nhóm mắt là: nhóm

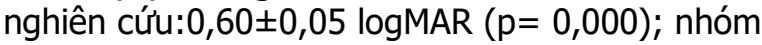

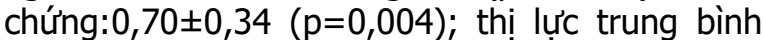
nhóm nghiên cứu khác với nhóm mắt chứng, với $\mathrm{p}=0,108$.

- Mức đô cải thiên thi lức của 2 nhóm mắt: nhóm mắt nghiên cứu: ổn định $66,7 \%$, tốt 23,3\%, giảm 10,0\%; nhóm chứng: ổn định $53,3 \%$, tốt 33,3\%, giảm 13,3\%; trong đó mức độ cải thiện thị lực của nhóm mắt NC khác so với nhóm mắt chứng với $p=0,760$.

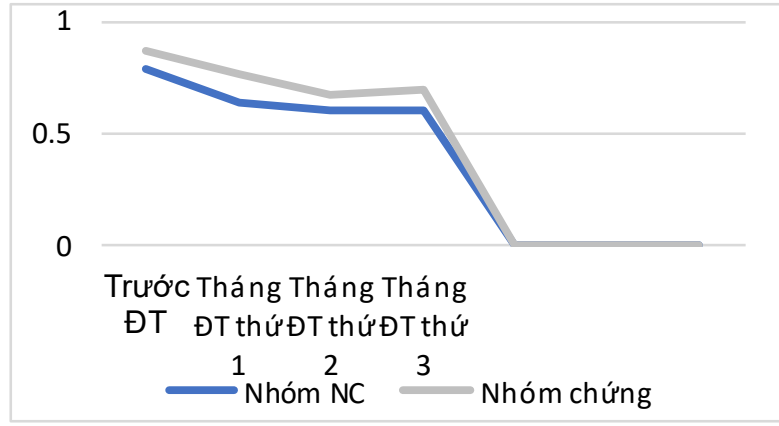

Biểu đồ 1. Sự thay đổi thị lực trung binh của 2 nhóm mắt qua các giai đoạn nghiên cứu

Có sự thay đổi khác nhau về thị lực giữa nhóm mắt $\mathrm{NC}$ và nhóm mắt chứng qua các giai đoạn điều trị.

*Nhãn áp. Nhãn áp trung bình của 2 nhóm mắt: nhóm $\mathrm{NC} 17,7 \pm 0,2 \mathrm{mmHg}$, thấp nhất là $15 \mathrm{mmHg}$, cao nhất là $20 \mathrm{mmHg}$, với $\mathrm{p}=0,538$; nhóm chứng $17,5 \pm 0,2 \mathrm{mmHg}$, thấp nhất là $16 \mathrm{mmHg}$, cao nhất là $22 \mathrm{mmHg}$, với $\mathrm{p}=0,305$. Nhãn áp 2 nhóm có sự khác biệt với $p=0,282$.

*Tai biến trong điều trị và biến chứng sau điều trị. Nhóm nghiên cứu không gặp tai biến hay biến chứng gì đáng lo ngại, có một số tác dụng phụ như: đau mắt và chảy nước mắt gắp $6 / 30$ mắt (2 nhóm), trợt giác mạc $1 / 30$ chiểm $3,3 \%$ ở nhóm mắt chứng.

\section{BÀN LUẬN}

Kết quả nghiên cứu cho thấy bệnh nhân bị phù hoàng điểm do đái tháo đường có giới tính nữ chiếm tỉ lệ cao hơn với 53\%; trong đó độ tuổi trung bình là $59,7 \pm 9,8$ tuổi; thấp nhất là 31 tuổi - mắc đái tháo đường typ 1, cao nhất là 77 tuổi mắc đái tháo đường type 2 , phù hợp với độ tuổi hay gặp của 2 type bệnh đái tháo đường.Nhóm bệnh nhân nghiên cứu của Fazel $F$ với cộng sự $(2020)^{5}$ và nghiên cứu của Ahmad Mirshahi với cộng sự (2019) ${ }^{8}$ cũng có sự tương đồng về độ tuổi trung bình. Bệnh nhân mắc chủ yếu đái tháo đường type 2 với $90 \%$ phù hợp với độ tuổi trung bình của nhóm bênh nhân nghiên cứu, và thuộc giai đoạn chưa tắng sinh của bệnh chiếm tỉ lệ cao $(80 \%)$ thuận lợi cho việc đánh giá hiệu quả, mức độ cải thiện về giải phẫu và chức năng trong điều trị phù hoàng điểm đơn thuần chính xác hơn. (khi chưa có tân mạch tăng sinh).

Đặc điểm phù hoàng điểm của 2 nhóm mắt trước điều trị có sự tương đồng về cả giải phẫu (chiều dày và thể tích vùng võng mạc trung tâm) và chức năng (thị lực, nhãn áp). Việc không có sự khác biệt này sẽ giúp cho việc đánh giá, so sánh kết quả điều trị của 2 nhóm đảm bảo tính khách quan và chính xác hơn.

Thuốc cố định timolol - dorzolamid với cơ chế làm duy trì nồng độ thuốc Bevacizumb cao, kéo dài trong buồng dịch kính, nhờ đó làm tăng hiệu quả điều tri của Bevacizumab tiêm nôi nhãn. Trên thế giới, đã có nhiều nghiên cứu đánh giá hiệu quả của việc phối hợp giữa thuốc cố định timolol - dorzolamid với Bevacizumab trong điều trị các bênh lý như: Thoái hóa hoàng điểm tuổi già, phù hoàng điểm do tắc tĩnh mạch võng mạc, hay phù hoàng điểm do đái tháo đường, bước đầu đều đạt hiệu quả tốt hơn so với nhóm điều trị Bevacizumab đơn thuần ${ }^{8}$. Nghiên cứu của chúng tôi bước đầu cũng thu được những kết quả khả quan về mặt giải phẫu và chức năng.

Về chiều dày vùng võng mac trung tâm (CMT) sau tháng điều trị thứ 3 , CMT trung bình của 2 nhóm đều giảm có ý nghĩa so với trước điều trị, trong đó nhóm mắt NC cho thấy hiệu quả có xu hướng giảm tốt hơn so với nhóm chứng, với $p=0,101>0,05$. Kết quả nghiên cứu của chúng tôi tương đồng với nghiên cứu của Ahmad Mirshahi và CS $(2019)^{8}$ về CMT trung bình của 2 nhóm, nghiên cứu của họ bước đầu thấy rõ được sự khác nhau giữa 2 nhóm, với $p<0,001$; nghiên cứu của Fazel $F$ và cs (sau 2 mũi IVB) cũng cho thấy sự giảm CMT trung bình có ý nghĩa thống kê ở cả 2 nhóm mắt, nhưng chưa thấy được sự khác biệt về sự thay đổi này giữa 2 nhóm, với $p=0,616>0,05$. Sự thay đổi về CMT trung bình của 2 nhóm qua các giai đoạn điều trị cũng có sự khác nhau, trong đó nhóm mắt NC giảm ổn định hơn so với nhóm mắt chứng (biểu đồ 2) trong khi trong nghiên cứu của Fazel $\mathrm{F}$ vs và $\mathrm{cs}^{5}$ lai chưa thây rõ được điêu này. Ngoài ra, mức độ cải thiện về CMT của 2 nhóm sau lần điều trị cuối chủ yếu là trung bình, và nhóm mắt NC cũng có mức độ cải thiện $\mathrm{CMT}$ tốt hơn so với nhóm chứng, với $\mathrm{p}=0,02<0,05$. 
Điều này chứng tỏ mức độ cải thiện về chiều dày võng mạc trung tâm của nhóm điêu trị phối hợp tốt hơn nhóm tiêm Bevacizumab đơn thuần trong nghiên cứu của chúng tôi.

Về thể tích vùng võng mạc trung tâm (CMV) sau tháng điều trị thứ 3 tiếp tục cho kết quả khả quan, CMV trung bình của 2 nhóm đều giảm có ý nghĩa thống kê so với trước nhưng sự khác nhau giữa 2 nhóm vẫn chưa có ý nghĩa thống kê,với $p=0,101>0,05$. Kết quả này của chúng tôi lại tương đồng với nghiên cứu của Fazel $\mathrm{F}$ và $\mathrm{CS}$ : có sự giảm CMV ở cả 2 nhóm sau tháng điêuu trị thứ 3 nhưng vẫn chưa có sự khác biệt giữa 2 nhóm, với $p=0,491>0,05$. Đồng thời, CMV trung bình qua các giai đoạn trong nghiên cứu của chúng tôi cũng thể hiện rằng nhóm mắt NC có xu hướng giảm tốt hơn nhóm mắt chứng (tương đồng với nghiên cứu của họ). Sự cải thiện về CMV giữa 2 nhóm NC (giảm 13,1\%) cao hơn nhóm chứng (giảm 10,6\%); lại có sự khác nhau không có ý nghĩa thống kê,với p=0,256>0,05.

Về chức năng, thị lực sau tháng điều trị thứ 3 trung bình của cả 2 nhóm đều tăng so với trước điều trị, trong đó thị lực trung bình của nhóm mắt NC có xu hướng tăng nhiều hơn so với nhóm mắt chứng, nhưng chưa có ý nghĩa thống kê, với $p=0,108>0,05$. Kết quả này cũng tương đồng với nghiên cứu với thời gian ngắn hơn nghiên cứu của chúng tôi, đó là nghiên cứu củacủa Fazel $F$ vs cs $(2020)^{5}$ - sau 2 mũi IVB, chưa thấy được sự thay đổi thị lực có ý nghĩa thống kê ở cả 2 nhóm hay sự khác biệt về thay đổi giữa 2 nhóm, với $p>0,05$. Nhưng nghiên cứu của Ahmad Mirshahi và cs (2019) ${ }^{8}$ - sau 3 mũi IVB, thây được sự khác biệt về thay đổi thị lực của 2 nhóm mắt, với $p=0,007$. Hơn nữa, nghiên cứu của nhóm chúng tôi còn cho thấy được sự thay đổi về thị lực trung bình của 2 nhóm mắt qua các giai đoạn cũng có sự khác nhau, nhóm mắt NC giảm nhanh và rõ rệt hơn so với nhóm mắt chứng (biểu đồ 1), rõ hởn so với nghiên cứu của Fazel $\mathrm{F}$ và cs. Mức độ cải thiện thị lực của 2 nhóm chủ yếu là ổn định, nhóm NC có mức độ cải thiện thị lực có xu hướng tốt hơn so với nhóm chứng, nhưng không có ý nghĩa thống kê, với $p=0,76>0,05$.

Về nhãn áp, nghiên cứu của chúng tôi chưa thấy được sự tác động của việc tiêm Bevacizumab nội nhãn (IVB) 2 nhóm mắt cũng như tra Azarga vào nhóm mắt NC đến nhãn áp của 2 nhóm mắt: sau tháng điều trị thứ 3, nhãn áp cả 2 nhóm vẫn trong giới hạn bình thường, sự khác biệt về thay đổi nhãn áp giữa 2 nhóm không có ý nghĩa thống kê, với $p=0,282>0,05$.
Trong khi nghiên cứu của Ahmad Mirshahi và $\mathrm{Cs}^{8}$ lại có sự hạ nhãn áp trung bình nhóm mắt NC, còn nhãn áp mắt chứng không đổi, với $p=0,038<0,05$. Điều này cho thây sự hợp lý trong tác dụng của thuốc đến việc điều chỉnh nhãn áp (với mắt NC tra Azarga).

Nghiên cứu của chúng tôi hiện không gặp tai biến hay biến chứng gì, chỉ gặp một số tác dụng phụ như: đau và chảy nước mắt $(20 \%$ - cả 2 nhóm), trợt giác mạc (3,3\%) ở nhóm chứng. Đây đều là những triệu chứng kích thích thường sau tiêm nội nhãn, gây khó chịu, kèm theo bệnh nhân dụi mắt nhiều gây nên (trợt giác mạc).

\section{KẾT LUẬN}

Việc phối hợp tra Azarga và tiêm Bevacizumab nội nhãn hay tiêm Bevacizumab đơn thuần trong điều trị phù hoàng điểm do đái tháo đường là phương pháp điều trị hiệu quả. Việc phối hợp tra Azarga và tiêm Bevacizumab nội nhãn bước đầu có xu hướng hiệu quả hơn việc tiêm Bevacizumab đơn thuần về giải phẫu và chức năng, nhưng bước đầu mới thể hiện rõ ở mức độ cải thiện về giải phẫu (chiều dày vùng võng mạc trung tâm).

\section{TÀI LIẸU THAM KHẢO}

1. Goyal S, Lavalley $M$, Subramanian ML. Metaanalysis and review on the effect of bevacizumab in diabetic macular edema. Graefe's archive for clinical and experimental ophthalmology = Albrecht von Graefes Archiv fur klinische und experimentelle Ophthalmologie. doi:10.1007/s00417-010-1452-4

2. Bakbak B, Ozturk BT, Gonul S, Gedik S. The effect of intravitreal bevacizumab and ranibizumab on macular edema of the contralateral eye: A comparative study of two anti-VEGFs. Oman journal of ophthalmology. 2016;9(1):44-48. doi:10.4103/0974-620X.176100

3. Miller K, Fortun JA. Diabetic Macular Edema: Current Únderstanding, Pharmacologic Treatment Options, and Developing Therapies. Asia Pac J Ophthalmol (Phila). 2018;7(1):28-35. doi:10.22608/APO.2017529

4. Takamura $\mathbf{Y}$, Ohkoshi K, Murata T. New Strategies for Treatment of Diabetic Macular Edema. Journal of ophthalmology. 2018;2018:4292154. doi:10.1155/2018/4292154

5. Fazel $F$, Nikpour $H$, Pourazizi M. Combination of Intravitreal Bevacizumab and Topical Dorzolamide versus Intravitreal Bevacizumab Alone for Diabetic Macular Edema: A Randomized Contralateral Clinical Trial. BioMed research international. 2020;2020:6794391. doi:10.1155/2020/6794391

6. Kaya C, Zandi S, Pfister IB, Gerhardt C, Garweg JG. Adding a Corticosteroid or Switching to Another Anti-VEGF in Insufficiently Responsive Wet Age-Related Macular Degeneration. Clinical ophthalmology. 
doi:10.2147/OPTH.S224456

7. Editorial Team. Dorzolamide/Timolol and Intravitreal Bevacizumab May Reduce Thickness in Eyes With Diabetic Macular Edema. EURETINA 2018. Published online September 28, 2018.

8. Ahmad MirshahiaRamin Tadayonib Navid Mohsenzadeha
RezvanicMojtabaAbrishamid. Efficacy of adjuvant topical timolol-dorzolamide with intravitreal bevacizumab injection in diabetic macular edema: A contralateral eye study. Journal of Current Ophthalmology. doi:doi.org/10.1016/j.joco.2019.01.008

\section{KHẢO SÁT TỈ LỆ VÀ SỰ ĐỀ KHÁNG KHÁNG SINH CỦA STAPHYLOCOCCUS EPIDERMIDIS PHÂN LÂPP TRÊN VÙNG DA RỐN VÀ BEN Ở BÊNH NHÂN TRƯớC PHẪU THUÂT TẠI BỆNH VIỆN ĐẠI HỌC Y DƯợC TP.HỒ CHÍ MINH}

\section{TÓM TẮT.}

Đắt vấn đề: Staphylococcus epidermidis ( $\mathrm{S}$. epidermidis) là tác nhân gây bệnh nhiê̂m khuẩn cơ hội, thường gặp trên da, niêm mạc của bệnh nhân khi được thực hiện can thiệp thủ thuật ngoại khoa. Các nghiên cứu cho thấy, tình trạng kháng kháng sinh của S. epidermidis ngày một nghiêm trọng. Mục tiêu: xác định tỉ lệ $\mathrm{S}$. epidermidis phân lập được trên vùng da rốn và bẹn ở bệnh nhân ngay trước phẫu thuật và tỉ lệ S. epidermidis đề kháng một số kháng sinh thường dùng. Phương pháp nghiên cứu: từ 218 bệnh nhân tham gia nghiên cứu, lấy bệnh phẩm quệt da bằng tăm bông vô khuẩn tại vùng da rốn hoặc bẹn tại ba thời điểm: sau khi bệnh nhân được tắm và gây mê (lần 1), sau khi điêuu dưỡng rửa da (lần 2), sau khi phẫu thuật viên sát khuẩn da (lần 3), thu thập được 654 bệnh phẩm. Tiến hành nuôi cấy, định danh bằng bộ trắc nghiện sinh hóa dành cho Staphylococci và hệ thống tự động $\mathrm{BD}$ Phoenix ${ }^{\mathrm{TM}} \mathrm{M} 50$, kháng sinh đồ bằng phương pháp khuếch tán đĩa giấy với 654 bệnh phẩm trên. Kết quả: tỉ lệ $S$. epidermidis tại vùng da rốn ở bênh nhân ngay trước phẫu thuật qua ba thời điểm lấy bệnh phẩm lần lượt là: 33,1\% (lần 1); 10,2\% (lần 2) và $1,8 \%$ (lần 3 ) và tỉ lệ có $S$. epidermidis tại vùng da ben ở bênh nhân ngay trước phẫu thuât qua ba thời điểm lấy bệnh phẩm lần lượt là: $32,7 \%$ (lân 1); $9,6 \%$ (lần 2 ) và $1,9 \%$ (lần 3 ). Tỉ lệ đề kháng kháng sinh của $\mathrm{S}$. epidermidis lần lượt quà ba thời điểm lấy bệnh phẩm: penicillin $(83,3 \% ; 95,5 \%$ và $100 \%)$; erythromycin (72,2\%; $86,4 \%$ và $100 \%)$; oxacillin $(58,3 \%$; $59,1 \%$ và $75 \%)$; trimethoprimsulfamethoxazole $(36,1 \% ; \quad 59,1 \%$ và $75 \%)$; ciprofloxacin $(30,6 ; 36,4$ và $0 \%)$; clindamycin $(16,7 \%$; $22,7 \%$ và $50 \%)$; levofloxacin $(22,2 \% ; 22,7 \%$ và $0 \%)$;

${ }^{1}$ Đại học Y Dược Thành phố Hồ Chí Minh Bệnh viện Đại học Y Dược Thành phố Hồ Chí Minh Chịu trách nhiệm chính: Huỳnh Minh Tuấn

Email: huynhtuan@ump.edu.vn

Ngày nhận bài: 10.8.2021

Ngày phản biện khoa học: 4.10.2021

Ngày duyệt bài: 14.10.2021
Trần Huy Cường ${ }^{1}$, Huỳnh Minh Tuấn ${ }^{1,2}$, Hoàng Tiến Mỹ ${ }^{1}$, Lý Khánh Vân ${ }^{1}$

tetracycline $(19,4 \% ; 22,7 \%$ và $0 \%)$; gentamycin $(20,8 \% ; 13,6 \%$ và $25 \%)$; doxycycline $(1,4 \% ; 0 \%$ và $0 \%$ ). Riêng với linezolid: $100 \%$ các chủng S. epidermidis phân lập được đều nhạy cảm. Kết luận: tỉ lệ phát hiện $\mathrm{S}$. epidermidis ở vùng da rốn và bẹn sau khi sát khuẩn da lần 3 là $1,8 \%$ và $1,9 \%$. $S$. epidermidis kháng với nhiều loại kháng sinh, từ 75$100 \%$ đối với penicillin, erythromycin, oxacillin nhưng còn nhay cảm với linezolid.

Tư khoá: S. epidermidis, đề kháng kháng sinh, bệnh nhân trước phấu thuật.

\section{SUMMARY}

\section{STAPHYLOCOCCUS EPIDERMIDIS AND IT'S} ANTIBIOTIC RESISTANCE ON THE SKIN OF UMBILICUS AND GROIN OF PRE-SURGERY PATIENTS AT UNIVERSITY MEDICAL CENTER IN HO CHI MINH CITY

Background: Staphylococcus epidermidis (S.epidermidis) an important opportunistic infection, most commonly on skin of patients who have had surgical interventions. Study shows that the antibiotic resistance of $\mathrm{S}$. epidermidis is more serious. Objective: To determine percentage of $\mathrm{S}$.epidermidis isolated on the skin of umbilicus and groin of presurgery patients and the rate resistance to antibiotics. Methods: Collecting 654 specimens with sterile cotton swabs from the skin of umbilicus or groin of 218 patients at three-time points: after the patient is bathed and anesthetized ( $1^{\text {st }}$ time), after the nurse washes the skin ( $2^{\text {nd }}$ time), after the surgeon disinfects the skin ( $3^{\text {rd }}$ time). Carrying out culture, identification by biochemical test kit for Staphylococci and BD Phoenix ${ }^{\mathrm{TM}}$ M50 automatic system, and testing the routine antibiotic susceptibility by the disc diffusion method with 654 samples. Results: Prevalences of S. epidermidis isolated on the umbilicus at three-time points: $33.1 \%\left(1^{\text {st }}\right.$ time $) ; 10.2 \%\left(2^{\text {nd }}\right.$ time $)$ and $1.8 \%$ ( $3^{\text {rd }}$ time). Prevalences of $\mathrm{S}$. epidermidis isolated on the groin at three-time points: $32.7 \%$ ( $1^{\text {st }}$ time); $9.6 \%\left(2^{\text {nd }}\right.$ time $)$ and $1.9 \%$ ( $3^{\text {rd }}$ time $)$. The rate of antibiotic resistance of $\mathrm{S}$. epidermidis over three-time points of specimen collection: penicillin (83.3\%; 